\title{
Genetics of reproductive performance in seasonal calving beef cows and its association with performance traits
}

\author{
D. P. Berry*1 and R. D. Evans $\uparrow$ \\ *Animal \& Grassland Research and Innovation Centre, Teagasc, Moorepark, \\ Co. Cork, Ireland; and †Irish Cattle Breeding Federation, Bandon, Co. Cork, Ireland
}

\begin{abstract}
Due primarily to a lack of phenotypic data, little research has been undertaken on the genetics of reproductive performance in beef cattle. The objective of this study was to quantify, using data from the Irish national cattle herd, the contribution of additive genetics to phenotypic differences in reproductive performance in beef cattle and to investigate whether routinely available early predictors of genetic merit for reproductive performance exist. Up to 218,718 parity records from 156,506 animals were used to estimate variance components for a range of reproductive traits using repeatability animal linear mixed models. Covariances with performance traits were estimated using bivariate sire linear mixed models. The reproductive traits were age at first calving, calving in the first $42 \mathrm{~d}$ of the calving seasons (defined separately in heifers and cows), calving interval between consecutive calving events, and survival to the next lactation. Performance traits included calving dystocia, linear type traits describing the skeletal,
\end{abstract}

muscular, and functional characteristics of an animal, live weight and price, carcass traits, and producer subjectively scored traits of weanling quality and docility. Heritability for age at first calving was 0.31 while the heritability of the remaining reproductive traits ranged from 0.01 to 0.06 ; repeatability estimates varied from 0.02 to 0.06 . Increased muscularity, measured either by trained assessors or producers on live animals, or by mechanical grading machines on slaughtered animals (i.e., carcass conformation), was genetically correlated with reduced reproductive performance for some of the reproductive variables assessed. This is one of the largest studies undertaken on the genetics of reproduction in beef herds and clearly shows that genetic selection for improved reproductive performance in beef herds is feasible. However, breeding goals that select for muscularity and live weight or growth rate should be cognizant of indirect response to selection that may cause any deterioration in reproductive performance.

Key words: beef, genetics, heritability, reproduction, survival

J. Anim. Sci. 2014.92:1412-1422 doi:10.2527/jas2013-6723

\section{INTRODUCTION}

Excellent reproductive efficiency is paramount to a profitable and sustainable national beef herd (Melton, 1995). Despite the low heritability commonly reported for most measures of reproductive performance in beef (Koots et al., 1994; Martínez-Velázquez et al., 2003; Donoghue et al., 2004) and dairy (Pryce and Veerkamp, 2001; Berry et al., 2013) cattle, the genetic variation present is sufficiently large enough (Gutiérrez et al., 2002; Berry et al., 2003; Goyache et al., 2005) to ensure breeding programs for reproductive performance

${ }^{1}$ Corresponding Author: Donagh.berry@teagasc.ie

Received May 20, 2013.

Accepted January 23, 2014. are successful. Although many studies have attempted to quantify the proportion of phenotypic differences in reproductive performance among beef animals due to additive genetic effects, these studies have generally been limited in the number of animals or herds included in the analysis (Evans et al., 1999; Phocas and Sapa, 2004; Urioste et al., 2007). Furthermore, few (Gregory et al., 1995; Roughsedge et al., 2005; Gutiérrez et al., 2007) evaluated the impact on reproduction caused by genetic selection on other economically important traits; these studies were generally limited in size and therefore lack precision in the estimates of especially the genetic correlations. Although some studies have evaluated the potential usefulness of early predictor traits for reproduction such as scrotal circumference in male relatives (Evans et al., 1999; Van 
Melis et al., 2010), few have evaluated the associations between traits describing the conformation (Gregory et al., 1995; Gutiérrez et al., 2002) or weight (Meyer et al., 1991; Gutiérrez et al., 2007; Crowley et al., 2011) of the animal and subsequent performance, despite such correlations existing in dairy cattle (Berry et al., 2003, 2004). Knowledge of these genetic parameters is a key component in evaluating the potential to genetically improve reproductive performance in beef herds.

The objective of this study, therefore, was to estimate genetic parameters for reproductive performance in beef herds. Genetic correlations between reproduction traits and other nationally recorded traits including live weight, docility, linear type traits, and carcass traits were also estimated. The results from this study will be useful in determining the feasibility of improving reproductive performance in Irish beef cattle through genetic selection but also to determine the long-term impact on reproductive performance from selection on other performance traits.

\section{MATERIALS AND METHODS}

Animal Care and Use Committee approval was not obtained for this study because the data were obtained from an existing database at the Irish Cattle Breeding Federation.

\section{Data Editing and Trait Definition}

Reproductive Performance and Survival. Calving dates from 1,632,941 cows totaling 5,127,232 calving events between the years 2002 and 2010 were available from 45,480 beef herds. Only data before one calendar year before a cow was used in embryo transfer were retained. The majority of animals were crossbred animals and all animals were Bos taurus.

Age at first calving was defined as the number of days from birth to first calving. Only age at first calving records between 660 and 1,278 d were retained. Calving interval was defined as the difference, in days, between 2 consecutive calving events within the same cow; only calving intervals between 300 and $800 \mathrm{~d}$ were retained.

Calving in the first $42 \mathrm{~d}$ of the calving season (CALV42) was defined as whether a cow calved in the first $42 \mathrm{~d}$ of the herd calving season (i.e., CALV42 $=1$ ) or did not calve in the first $42 \mathrm{~d}$ of the herd calving season (i.e., CALV42 $=0$ ). The calving season was defined separately for primiparae and multiparae. The start of the calving season was defined as the first calving date, within herd, when at least 5 cows calved within the subsequent $14 \mathrm{~d}$. The end of the calving season was defined as the last calving, within herd, which was not followed by a subsequent calving within $21 \mathrm{~d}$. Only calving seasons between 35 and $200 \mathrm{~d}$ in length were retained and each calving season had to have at least 5 and 10 calving events for primiparae and multiparae, respectively.
Survival (referred to as stayability in some studies) was defined as whether or not a cow survived from lactation $i$ to lactation $i+1$. A cow was assumed not to have survived lactation $i$ if she did not have a calving record for lactation $i+1$ and the difference between the cow's last recorded calving date was $>800 \mathrm{~d}$ from the last recorded calving date for that herd or if the cow was slaughtered or died on farm within $400 \mathrm{~d}$ of calving in parity $i$.

Following the removal of animals with no known sire and parity records greater than 10 , information on either of the 4 reproduction traits were available on 281,718 lactations from 156,506 cows. Contemporary group was defined separately for all traits. For age at first calving and CALV42 in primiparae, the contemporary group was herd-year-season of service and was based on the herd the heifer resided in 9 mo before first calving. Only heifers remaining in the same herd from 9 to 15 mo before first calving were considered for inclusion in the analysis. This approach was used to account for the movement of heifers between farms. Date of service was approximated as $282 \mathrm{~d}$ before first calving. For calving interval, CALV42 in multiparae, and survival, contemporary group was herd-year-season of calving and was defined across parities. In all instances the definition of herd-year-season was based on the algorithm described in detail by Schmitz et al. (1991) and Crump et al. (1997) and used in previous Irish genetic studies (McHugh et al., 2011; Berry et al., 2013). The algorithm is based on grouping animals together, within herd, that have dates in close proximity. Initially, dates differing by a predefined number of days (in this study $10 \mathrm{~d}$ was chosen) are placed in separate contemporary groups. Subsequently, if the number of records within any contemporary group was less than a predefined number (10 was chosen in the present study), they were merged with a contemporary group adjacent in time if the start date and end date of the adjacent contemporary groups was less than a specified number (in this study $182 \mathrm{~d}$ was used as the threshold).

For age at first calving and CALV42 in primiparae, only contemporary groups with at least 4 animals were retained while for calving interval, CALV42 in multiparae and survival the threshold was contemporary groups of at least 5 animals. A random subset of contemporary groups was retained for the multiparae traits to achieve a target dataset size of approximately 100,000 records to facilitate variance component estimation. The number of animals and number of contemporary groups included in the final analyses for each trait is detailed in Table 1.

Calving Difficulty. In Ireland calving difficulty is scored by producers on a scale of 1 to 4 as follows: $1=$ no assistance, $2=$ slight assistance, $3=$ considerable assistance, and $4=$ veterinary assistance (including caesarean operations). Calving dates from 1,632,941 cows totaling 5,127,232 calving events between the years 2002 
Table 1. Number of records $(n)$ and contemporary groups (CG), raw mean and phenotypic standard deviation, and direct heritability $\left(\mathrm{h}^{2}\right)$ and repeatability estimates for the reproduction traits, calving dystocia, cow live weight, price, and carcass traits

\begin{tabular}{|c|c|c|c|c|c|c|}
\hline Trait & $n$ & No. of CG & Mean & SD & $\mathrm{h}^{2}(\mathrm{SE})$ & Repeatability (SE) \\
\hline Age at first calving, $\mathrm{d}$ & 64,380 & 10,576 & 936 & 150.5 & $0.31(0.016)$ & \\
\hline \multicolumn{7}{|l|}{ Calving in first $42 \mathrm{~d}$ of breeding season } \\
\hline Heifers, \% & 40,671 & 6,073 & 0.91 & 0.284 & $0.06(0.013)$ & \\
\hline Cows, $\%$ & 106,419 & 9,630 & 0.82 & 0.386 & $0.01(0.003)$ & $0.06(0.005)$ \\
\hline Calving interval, $\mathrm{d}$ & 101,864 & 11,980 & 384 & 51.4 & $0.02(0.004)$ & $0.05(0.007)$ \\
\hline Survival, \% & 104,117 & 11,859 & 0.85 & 0.358 & $0.02(0.003)$ & $0.02(0.003)$ \\
\hline Cow price, $€$ & 18,009 & 3,010 & 501 & 266.2 & $0.30(0.046)$ & \\
\hline Cow carcass weight, $\mathrm{kg}$ & 109,222 & 11,724 & 312 & 54.8 & $0.17(0.014)$ & \\
\hline Cow carcass conformation (scale 1 [poor] to 15 [good]) & 109,222 & 11,724 & 3.6 & 2.13 & $0.62(0.026)$ & \\
\hline Cow carcass fat grade (scale 1 [fat] to 15 [high]) & 109,222 & 11,724 & 6.6 & 2.49 & $0.18(0.012)$ & \\
\hline
\end{tabular}

${ }^{1}$ Maternal heritability (SE) was $0.06(0.110)$.

and 2010 were available from 45,480 beef herds. In the present study, where multiple births existed, only 1 record for that calving event was retained; the most difficult dystocia score recorded for either of the births were retained. Only calvings from parity 1 to 10 were retained. Following these edits as well as the removal of records where either the sire of the calf or the sire of the dam were unknown, 567,787 calving events from 240,281 beef cows remained. Contemporary group was defined, across parities, as herd-year-season of calving using the algorithm previously described. Only contemporary groups with at least some incidence of dystocia were further retained. A subset of contemporary groups was retained to achieve a target dataset size of approximately 100,000 records to facilitate variance component estimation. Following all edits 100,445 dystocia records remained (Table 1).

Linear Type Traits. Linear scoring in Ireland is routinely performed in pedigree beef herds and to a lesser extent in commercial beef herds as part of the national breeding program. Linear scoring is a subjective assessment of the muscular, skeletal, and functional characteristics of an animal. Linear score data were available on 64,557 animals, aged between 183 and $365 \mathrm{~d}$ of age, from 5,010 beef herds. Scoring was undertaken by 25 trained scorers. In total 28 different traits were assessed; 20 traits scored across breeds were retained in this study. Each trait was standardized, within scorer by year, to a common variance within trait as described by Brotherstone (1994). The subjective measurements represented the skeletal, muscle, and functionality characteristics of the animal as well as scores for docility and BCS. Only animals with a known sire were retained. Contemporary group was defined as herd-date of scoring and only records from contemporary groups with at least 5 scored animals were retained. Following all edits, linear scores on 35,669 animals aged between 6 and 12 mo were available.
Producer Scored Docility and Animal Quality. In 2008 the Irish Department of Agriculture launched a new voluntary participation scheme for Irish beef herds called the Animal Welfare, Recording and Breeding Scheme for Suckler Herds. The scheme was open to commercial beef cattle and cattle registered with a breed society. A component of the scheme involved the producer subjectively recording docility on a scale of 1 (docile) to 5 (aggressive) at weaning; animal quality at weaning, assessed subjectively by the producer, was also scored on a scale of 1 (very poor) to 5 (very good). Animals were only scored once during their lifetime.

A total of 1,433,060 animals from 34,510 herds scored between 2008 and 2010 were available. Contemporary group was defined as herd-date of scoring. Only records from contemporary groups with some variation in both docility and quality scores were retained. Additionally, only animals scored between 183 and $365 \mathrm{~d}$ of age with a known sire and from a contemporary group with at least 5 records were retained. Following editing, 437,871 records remained. A random sample of contemporary groups was taken to result in approximately 100,000 animals for estimation of variance components; following sampling 103,427 animals from 7,547 contemporary groups in 6,210 herds remained (Table 2).

Animal Live Weight and Price. In Ireland, livestock auctions, selling animals of all ages, are held at different venues throughout the country known as marts. In this study, animal live weight and price data were available from 71 different marts representing the majority of marts in Ireland. A total of 1,528,497 records with both animal live weight and price were available from 1,357,535 animals sold singly between the years 2002 to 2010. As part of the national breeding program, progeny of test sires as well as commercial contemporaries were also weighed on commercial farms and these data were captured. A 
Table 2. Number of animals and contemporary groups (CG), raw mean and phenotypic standard deviation, and direct heritability $\left(\mathrm{h}^{2}\right)$ estimates for the weanling and postweanling traits, carcass traits, and producer scored weanling docility and quality

\begin{tabular}{|c|c|c|c|c|c|}
\hline Trait & No. of animals & No. of CG & Mean & SD & $\mathrm{h}^{2}(\mathrm{SE})$ \\
\hline Weanling live weight, ${ }^{1} \mathrm{~kg}$ & 60,731 & 6,001 & 345 & 78.8 & $0.27(0.021)$ \\
\hline Weanling price, $€$ & 33,826 & 4,014 & 616 & 148.6 & $0.38(0.076)$ \\
\hline Postweanling live weight, $\mathrm{kg}$ & 42,905 & 5,506 & 462 & 90.4 & $0.43(0.028)$ \\
\hline Postweanling price, $€$ & 42,905 & 5,506 & 717 & 179.9 & $0.61(0.027)$ \\
\hline Carcass weight, $\mathrm{kg}$ & 100,838 & 7,473 & 340 & 60.2 & $0.82(0.026)$ \\
\hline Carcass conformation (scale 1 [poor] to 15 [good]) & 100,838 & 7,473 & 6.6 & 2.38 & $0.60(0.023)$ \\
\hline Producer scored weanling quality (scale 1 [poor] to 5 [excellent]) & 103,427 & 7,547 & 2.41 & 0.78 & $0.26(0.018)$ \\
\hline
\end{tabular}

${ }^{1}$ Maternal heritability was $0.18 \pm 0.01$.

total of 1,235,620 records from 1,091,585 animals, aged between 150 and 1,095 d, collected from 73,829 herds between the years 2002 to 2010 were also available in this study; no price data were available on these animals.

Animals were characterized as weanlings, postweanlings, and cows as outlined in detail by McHugh et al. (2010). Weanlings were defined as males and females aged between 6 and 12 mo at weighing. Postweanlings were defined as females aged between 12 and 30 mo and males aged between 12 and 36 mo; females that had a calving date before weighing or sale were not included as postweanlings. Cows were defined as females with at least 1 recorded calving event or greater than $30 \mathrm{mo}$ at the time of sale. Only cows less than $12 \mathrm{yr}$ of age were retained.

Only weanling sold for between $€ 200$ and $€ 1,200$, postweanlings sold for between $€ 200$ and $€ 1,500$, and cows sold for between $€ 75$ and $€ 1,500$ were retained (McHugh et al., 2010). Weanlings had to weigh between 150 and $900 \mathrm{~kg}$, postweanlings had to weigh between 200 and $1,000 \mathrm{~kg}$, and cows had to weigh between 300 and $1,000 \mathrm{~kg}$ (McHugh et al., 2010). McHugh et al. (2011) reported a maternal variance for weaning weight and therefore weight records from weanlings with no known maternal grandsire were omitted; this edit was only applied to weanlings. Only animals with a known sire were retained and only the first record in time for the weanlings and postweanlings and the last record in time for the cows were retained. Each category of animal was treated as separate traits in the subsequent analyses.

Cows were classified both on their fate postsale and days since last calving when sold. Fate postsale was categorized based on 4 possibilities. Where data on next calving were known, cows were grouped in days to next calving: less than $50 \mathrm{~d}, 51$ to $100 \mathrm{~d}, 101$ to $200 \mathrm{~d}, 201$ to $300 \mathrm{~d}$, and greater than $300 \mathrm{~d}$. Cows that were destined for slaughter were grouped into 6 groups: cows slaughtered within $3 \mathrm{~d}$ postsale, 4 to $50 \mathrm{~d}, 51$ to $100 \mathrm{~d}, 101$ to $200 \mathrm{~d}$, 201 to $300 \mathrm{~d}$, and greater than $300 \mathrm{~d}$. Where cows calved again in their lifetime but were eventually slaughtered, fate postsale based on subsequent calving took precedence over fate postsale based on slaughter. Cows not allocated to either category were allocated a separate code.

Cows were also grouped on their days since last calving at the time of selling: less than $50 \mathrm{~d}$ postcalving, 51 to $100 \mathrm{~d}, 101$ to $200 \mathrm{~d}, 201$ to $300 \mathrm{~d}$, and greater than $300 \mathrm{~d}$. Females greater than 30 mo of age but with no recorded calving date were allocated a separate code.

For both live weight and price, two contemporary groups were defined: mart by date of sale and herd-yearseason of sale defined using the algorithm previously described for the generation of contemporary groups. Only contemporary groups with at least five records were retained. The number of records remaining for inclusion in the analysis is summarized in Tables 1 and 2.

Carcass Traits. Data on carcass conformation, carcass fat, and carcass weight on 6,586,198 animals slaughtered between 2005 and 2010 were available; mechanical grading of cattle carcasses has been used in Irish abattoirs since 2005. Carcass weight is measured, on average, $2 \mathrm{~h}$ after slaughter after the removal of the head, legs, thoracic and abdominal organs, internal fats, and hide (Hickey et al., 2007). In the present study the EUROP classification grades for carcass conformation and carcass fat, scored on all carcasses, were transformed to a 15-point linear scale as outlined by Hickey et al. (2007).

Cows were defined as females that had calved at least once or were greater than 30 mo of age at the time of slaughter; only cows slaughtered less than $12 \mathrm{yr}$ of age were retained. Cows were treated separately to other cattle in the present study. Of the remaining cattle only males slaughtered between 300 and 1,200 d of age and females slaughtered between 300 and $875 \mathrm{~d}$ of age were retained. Irrespective of animal, carcass weight records less than $150 \mathrm{~kg}$ and greater than $550 \mathrm{~kg}$ were omitted. Only animals with a known sire were retained. Cows were grouped on the number of days since last calving to slaughter: less than $50 \mathrm{~d}$ postcalving, 51 to $100 \mathrm{~d}, 101$ to $200 \mathrm{~d}, 201$ to $300 \mathrm{~d}$, and greater than $300 \mathrm{~d}$. Females 
greater than 30 mo of age but with no recorded calving date were allocated a separate code.

Contemporary group was defined separately for cows and other cattle as herd by season of slaughter by sex and abattoir by slaughter date; only contemporary groups with five or more records were retained. The contemporary group of herd-season of slaughter-sex was generated using the algorithm previously described to group animals of the same sex and herd slaughtered in close proximity in time. A random sample of contemporary groups was taken to result in approximately 100,000 animals for estimation of variance components. Following sampling a total of 109,222 cows from 11,724 contemporary groups (Table 1) and 100,838 progeny carcasses from 7,473 contemporary groups (Table 2) with information on carcass weight, carcass conformation, and carcass fat remained.

\section{Heterosis and Recombination Loss}

Heterosis and recombination loss regression coefficients were calculated for each animal as

$$
1-\sum_{i=1}^{n} \operatorname{sire}_{i} \times \operatorname{dam}_{i} \text { and } 1-\sum_{i=1}^{n} \frac{\operatorname{sire}_{i}^{2}+\operatorname{dam}_{i}^{2}}{2},
$$

respectively, in which sire ${ }_{i}$ and dam $_{i}$ are the proportion of breed $i$ in the sire and dam, respectively (VanRaden and Sanders, 2003).

\section{Estimation of Genetic Parameters}

Variance components for all traits were estimated using animal models in ASReml (Gilmour et al., 2009) with the exception of calving difficulty and maternal weaning weight, which used an animal-dam model; no covariance was fitted between the animal and dam component. Calving interval, CALV42 in multiparae, and survival were all analyzed using a repeatability animal model (i.e., animal permanent environmental effects was included in the model). Covariance components among the reproduction traits themselves and between the reproduction traits and the other performance traits were estimated using a series of bivariate sire linear mixed models. The exceptions were calving difficulty and maternal weaning weight where a sire-maternal grandsire model was fitted. When the analysis was undertaken on multiparae cows, a permanent environmental variance was also estimated.

Fixed effects included in the model for all reproduction traits were contemporary group, a single general heterosis coefficient term, and a single general recombination loss coefficient term; parity was included in the model for the analysis of calving interval, CALV42, and survival. With the exception of producer scored animal quality and docility, the fixed effects included in the models for the other traits have been described elsewhere
(Crowley et al., 2010; McHugh et al., 2011; Pabiou et al., 2011). Contemporary group or groups was included in the model as a fixed effect for all traits and gender was included when more than one gender was included in the analysis but not implicitly assumed within the definition of contemporary group. Age at the time of the relevant event (e.g., slaughter), heterosis, and recombination loss coefficient of the animal were also included in all models, where significant $(P<0.05)$ as continuous variables with nonlinear associations for all of the continuous variables also tested; interactions between age and gender were also investigated where gender was also included in the model as a main effect. Where significant $(P<0.05)$, parity of the dam was also included in the model. For cow BW and price, fate postcalving and days since last calving were included as class effects; for cow carcass traits, days since last calving was included in the model. For the producer scored animal quality and docility the fixed effects included in the model were contemporary group, age of the animal at scoring, and both heterosis and recombination loss coefficient terms.

The pedigree of each animal (and dam in the case of animal-dam models) was traced back to the base population, and founder animals were allocated to breed groups $(n=11)$ based on breed. The pedigree file consisted of 1,015,250 individuals.

\section{RESULTS}

The frequency distribution of the calvings across the year for the 5,127,232 calving events in the original dataset from the 45,480 beef herds is in Fig. 1. Calving pattern was seasonal with $67 \%$ of cows calved between February and May, inclusive. The mean performance of each trait is summarized in Tables 1 and 2. Cows calved for the first time at over 30 mo of age (i.e., $936 \mathrm{~d}$ ) with a mean calving interval thereafter of $384 \mathrm{~d}$. With the exception of the moderate heritability for age at first calving (0.31), the heritability of the reproduction traits were $\leq 0.06$ (Table 1 ). The repeatability of the cow reproduction traits was also low (Table 1). Average cow carcass weight at slaughter was $312 \mathrm{~kg}$ (Table 1); average carcass weight of the progeny was $340 \mathrm{~kg}$ (Table 2). Heritability of the two producer scored weanling traits, weanling docility and weanling quality, were 0.69 and 0.78 , respectively (Table 2) with considerable genetic variation also present; the coefficient of genetic variation for docility and quality was 0.13 and 0.08 , respectively. Heritability of the linear type traits is reported elsewhere (McHugh et al., 2012) and ranged from 0.14 (front-leg front view) to 0.52 (hind-quarter development). The genetic correlations among the 5 reproduction traits are detailed in Table 3. Animals genetically predisposed to calving for the first time at an older age had inferior (i.e., 


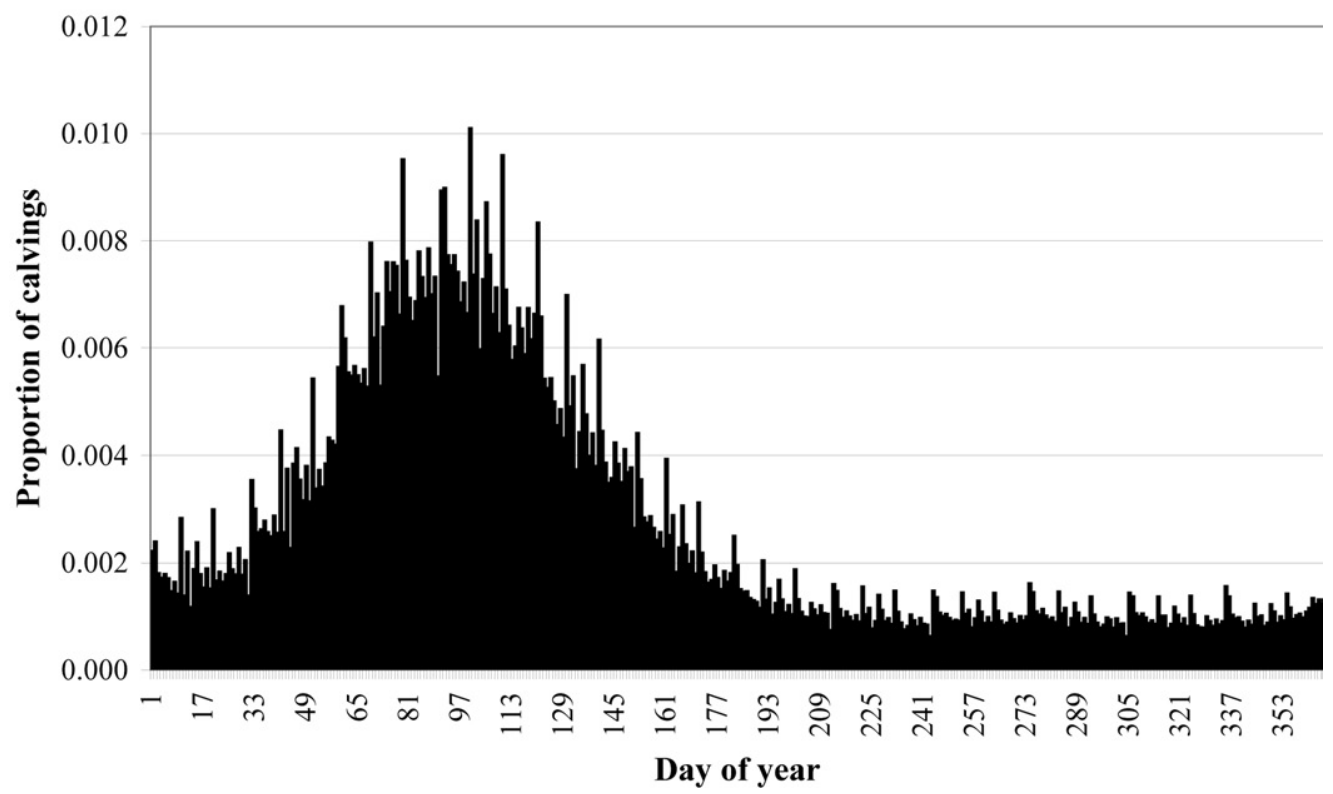

Figure 1. Frequency distribution of the calving events in the beef herds for each day of the year (Day 1 = January 1).

longer) genetic merit for calving interval. Genetic merit for calving interval was an important contributor to the genetic differences in survival as evidenced by the moderate negative genetic correlation between the two traits $(-0.63$; Table 3$)$.

\section{Genetic Correlations between Reproduction and the Linear Type Traits}

Although not always more than $2 \mathrm{SE}$ from 0 , genetically taller, longer, and wider animals were of inferior genetic merit for reproductive performance (Table 4). However, albeit also associated with large SE, genetic merit for greater animal size was associated with genetically longer survival. Genetic correlations between the muscular type traits and both age at first calving and CALV42 in heifers were near 0. Antagonistic genetic correlations, however, existed between muscularity and both CALV42 in cows (genetic correlations ranged from -0.47 to -0.07 ) and calving interval (genetic correlations ranged from 0.17 to 0.34 ). Increased genetic merit for muscularity was, nonetheless, associated with superior genetic merit for survival. Animals with genetically good locomotion had better reproductive performance and survival as had animals in genetically better BCS.

\section{Genetic Correlations between Reproduction and Live Weight, Price, and Carcass Traits}

Although not always consistent, live weight either as a cow, weanling (i.e., direct live weight), or postweanling was generally negatively associated (or close to 0 ) with CALV42 in cows and heifers and was positively associated with both calving interval and survival (Table 5); the exceptions were the positive genetic correlation $(0.21 \pm$ 0.14 ) between postweanling live weight and CALV42 in heifers and the negative genetic correlation $(-0.33 \pm 0.20)$ between cow live weight and survival. The genetic correlations between live weight and reproductive performance were substantiated by the same sign genetic correlations between the reproduction traits and carcass weight. The genetic correlations between the reproduction traits with maternal weaning weight were opposite in direction to the correlations with direct weaning weight with no correlation observed between maternal weaning weight and survival (Table 5). Moderate to strong genetic correlations existed between animal price in both weanlings and postweanling and CALV42 in cows $(-0.87$ and -0.61 for weaning price and postweaning price, respectively), calving interval (0.64 and 0.74 for weaning price and postweaning price, respectively), and survival ( 0.27 and 0.57 for weaning price and postweaning price, respectively); genetic correlations

Table 3. Genetic correlations (SE in parenthesis) between the 5 reproduction traits

\begin{tabular}{|c|c|c|c|c|}
\hline \multirow[b]{2}{*}{ Trait } & \multirow{2}{*}{$\begin{array}{c}\text { Age at } \\
\text { first calving }\end{array}$} & \multicolumn{2}{|c|}{ Calving in the first $42 \mathrm{~d}$ of the calving season } & \multirow{2}{*}{$\begin{array}{l}\text { Calving } \\
\text { interval }\end{array}$} \\
\hline & & Heifers & Cows & \\
\hline Calving in the first $42 \mathrm{~d}$ of the calving season: heifers & $0.35(0.07)$ & & & \\
\hline Calving in the first $42 \mathrm{~d}$ of the calving season: cows & $-0.25(0.13)$ & $0.31(0.20)$ & & \\
\hline Calving interval & $0.22(0.10)$ & $-0.27(0.16)$ & $-0.45(0.20)$ & \\
\hline Survival & $0.28(0.10)$ & $-0.08(0.19)$ & $0.59(0.15)$ & $-0.63(0.17)$ \\
\hline
\end{tabular}


Table 4. Scale of measurement of the linear type traits and genetic correlations (SE in parenthesis) between the linear type traits and reproduction

\begin{tabular}{|c|c|c|c|c|c|c|}
\hline \multirow[b]{2}{*}{ Trait } & \multirow[b]{2}{*}{ Scale } & \multirow{2}{*}{$\begin{array}{c}\text { Age at } \\
\text { first calving }\end{array}$} & \multicolumn{2}{|c|}{ Calving in the first $42 \mathrm{~d}$ of calving season } & \multirow{2}{*}{$\begin{array}{l}\text { Calving } \\
\text { interval }\end{array}$} & \multirow[b]{2}{*}{ Survival } \\
\hline & & & Heifers & Cows & & \\
\hline Skeletal & 1 to 10 & & & & & \\
\hline Chest width & Narrow to wide & $0.08(0.106)$ & $-0.33(0.160)$ & $-0.43(0.250)$ & $0.09(0.183)$ & $0.58(0.156)$ \\
\hline Length of back & Short to long & $-0.07(0.074)$ & $-0.14(0.125)$ & $-0.45(0.178)$ & $0.14(0.136)$ & $0.27(0.149)$ \\
\hline Length of pelvis & Short to long & $-0.13(0.092)$ & $-0.28(0.145)$ & $-0.21(0.225)$ & $-0.09(0.164)$ & $0.14(0.188)$ \\
\hline Width at pelvis & Narrow to wide & $-0.07(0.089)$ & $-0.21(0.140)$ & $-0.25(0.214)$ & $0.35(0.146)$ & $0.00(0.176)$ \\
\hline Width at hips & Narrow to wide & $-0.07(0.076)$ & $-0.16(0.131)$ & $-0.50(0.195)$ & $0.01(0.146)$ & $0.36(0.154)$ \\
\hline Depth of rump & Shallow to deep & $0.06(0.085)$ & $-0.42(0.133)$ & $-0.29(0.220)$ & $0.07(0.161)$ & $0.66(0.140)$ \\
\hline Muscle & 1 to 15 & & & & & \\
\hline Loin development & Low to high & $0.04(0.074)$ & $-0.02(0.131)$ & $-0.47(0.194)$ & $0.17(0.144)$ & $0.38(0.145)$ \\
\hline Development of inner thigh & Low to high & $0.09(0.083)$ & $-0.24(0.138)$ & $-0.31(0.206)$ & $0.34(0.146)$ & $0.13(0.173)$ \\
\hline Functional and other & 1 to 10 & & & & & \\
\hline Fore leg, front view & Toes out to toes in & $-0.05(0.122)$ & $0.01(0.183)$ & $-0.11(0.258)$ & $0.33(0.188)$ & $0.15(0.215)$ \\
\hline Hind leg, side view & Straight to sickled & $0.32(0.093)$ & $0.07(0.159)$ & $-0.25(0.234)$ & $0.23(0.168)$ & $-0.16(0.194)$ \\
\hline Hind leg, rear view & Toes out to toes in & $0.07(0.104)$ & $0.48(0.147)$ & $-0.59(0.229)$ & $0.22(0.175)$ & $-0.04(0.209)$ \\
\hline Locomotion & Poor to good & $-0.28(0.084)$ & $-0.06(0.150)$ & $-0.15(0.217)$ & $0.26(0.161)$ & $0.39(0.165)$ \\
\hline Body condition score & Lean to fat & $0.14(0.108)$ & $-0.35(0.167)$ & $-0.01(0.190)$ & $-0.18(0.186)$ & $0.70(0.155)$ \\
\hline Docility & Aggressive to docile & $0.08(0.079)$ & $-0.18(0.131)$ & $-0.02(0.193)$ & $0.04(0.145)$ & $0.04(0.164)$ \\
\hline
\end{tabular}

between the reproduction traits and cow price were weak $(-0.28$ to 0.17 ; SE ranged from 0.12 to 0.25$)$

Genetic merit for greater carcass subcutaneous fat score, in either cows or progeny, was associated with genetic merit for superior reproductive performance and survival although the correlation with survival was not different from 0 . Genetic correlations between the reproduction traits and cow carcass conformation were close to 0 ( -0.18 to 0.19$)$. Genetic merit for better carcass conformation of progeny was associated with genetically longer calving intervals and better survival.

\section{Genetic Correlations between Reproduction and Calving Dystocia, Weanling Quality, and Weanling Docility}

Greater genetic susceptibility to direct calving difficulty was associated with older age at first calving while the opposite was true for genetic merit for maternal calving difficulty (Table 6). Greater direct calving difficulty was associated with reduced CALV42 in both heifers and cows (Table 6). Greater direct or maternal calving difficulty was associated with longer calving intervals and reduced survival (Table 6).

Table 5. Genetic correlations (SE in parenthesis) between live weight, price, and carcass traits and reproduction

\begin{tabular}{|c|c|c|c|c|c|}
\hline \multirow[b]{2}{*}{ Trait } & \multirow{2}{*}{$\begin{array}{c}\text { Age at } \\
\text { first calving }\end{array}$} & \multicolumn{2}{|c|}{ Calving in the first $42 \mathrm{~d}$ of calving season } & \multirow{2}{*}{$\begin{array}{l}\text { Calving } \\
\text { interval }\end{array}$} & \multirow[b]{2}{*}{ Survival } \\
\hline & & Heifers & Cows & & \\
\hline Cow live weight & $-0.05(0.121)$ & $-0.34(0.212)$ & $-0.13(0.260)$ & $0.54(0.187)$ & $-0.33(0.202)$ \\
\hline Cow price & $0.09(0.116)$ & $0.05(0.209)$ & $0.27(0.233)$ & $-0.02(0.187)$ & $-0.15(0.193)$ \\
\hline Cow carcass weight & $0.11(0.059)$ & $-0.04(0.117)$ & $-0.13(0.156)$ & $0.34(0.116)$ & $0.26(0.118)$ \\
\hline Cow carcass conformation & $0.06(0.050)$ & $0.00(0.102)$ & $-0.18(0.138)$ & $0.19(0.105)$ & $0.08(0.110)$ \\
\hline Cow carcass fatness & $0.18(0.073)$ & $0.07(0.135)$ & $0.37(0.169)$ & $-0.44(0.128)$ & $0.18(0.141)$ \\
\hline Weaning price & $-0.05(0.076)$ & $0.16(0.143)$ & $-0.86(0.125)$ & $0.64(0.087)$ & $0.26(0.109)$ \\
\hline Postweaning weight & $0.09(0.073)$ & $0.21(0.137)$ & $-0.21(0.178)$ & $0.70(0.070)$ & $0.44(0.090)$ \\
\hline Postweaning price & $0.01(0.055)$ & $-0.37(0.111)$ & $-0.70(0.115)$ & $0.50(0.079)$ & $0.51(0.071)$ \\
\hline Progeny carcass weight & $-0.07(0.048)$ & $0.04(0.100)$ & $-0.05(0.154)$ & $0.22(0.112)$ & $0.26(0.118)$ \\
\hline Progeny carcass conformation & $0.01(0.047)$ & $0.04(0.090)$ & $-0.15(0.149)$ & $0.29(0.107)$ & $0.26(0.106)$ \\
\hline
\end{tabular}


Table 6. Genetic correlations (SE in parenthesis) with reproduction for calving dystocia, and both docility and quality of the weanling subjectively assessed by the producer

\begin{tabular}{|c|c|c|c|c|}
\hline \multirow[b]{2}{*}{ Trait } & \multicolumn{2}{|c|}{ Dystocia } & \multirow{2}{*}{$\begin{aligned} & \text { Weanling docility } \\
(1= & \text { docile } 5=\text { aggressive })\end{aligned}$} & \multirow{2}{*}{$\begin{array}{c}\text { Weanling quality } \\
(1=\text { very poor; } 5=\text { very good })\end{array}$} \\
\hline & Direct effect & Maternal effect & & \\
\hline Age at first calving & $0.28(0.058)$ & $-0.22(0.076)$ & $0.46(0.067)$ & $-0.33(0.076)$ \\
\hline \multicolumn{5}{|c|}{ Calving in the first $42 \mathrm{~d}$ of calving season } \\
\hline Heifers & $-0.20(0.114)$ & $0.13(0.136)$ & $-0.51(0.128)$ & $-0.44(0.134)$ \\
\hline Cows & $-0.80(0.145)$ & $0.18(0.126)$ & $-0.45(0.193)$ & $-0.54(0.207)$ \\
\hline Calving interval & $0.18(0.126)$ & $0.32(0.119)$ & $0.16(0.153)$ & $0.44(0.138)$ \\
\hline
\end{tabular}

Genetically, more docile animals were older at first calving and had inferior reproductive performance; the genetic correlation between docility and survival was not different from 0 (Table 6). Genetic merit for superior weanling quality was associated with younger age at first calving and inferior reproductive performance (Table 6).

\section{DISCUSSION}

In comparison to dairy cows (Pryce and Veerkamp, 2001; Berry et al., 2013), few analyses from national datasets are available on the contribution of additive genetics to differences in reproductive performance of beef cows. Most previous studies on the genetics of reproductive performance in beef cattle are limited in size (Evans et al., 1999; Phocas and Sapa, 2004; Bormann et al., 2006; Urioste et al., 2007) and therefore have large associated SE of estimated parameters. The objective of this study was to estimate genetic parameters for reproductive traits, especially pertinent to seasonal calving beef production systems. Such information could subsequently be incorporated into national genetic evaluations to guide producers in selection decisions.

\section{Population Statistics and Heritability Estimates}

Seasonal calving systems predominate in Ireland (Fig. 1) with the peak period of calving coinciding with the initiation of grass growth. The goal of such a production system is to maximize the use of grazed grass in the diet of the beef herd thereby minimizing the feed cost of the herd. A successful seasonal calving beef herd is characterized by 1) heifers calving early in the calving season at a suitably young age without any deleterious long-term effects, 2) cows returning to cyclicity early postcalving and both establishing and maintaining pregnancy thereby calving early in the subsequent calving season or in other words a calving interval of approximately $365 \mathrm{~d}$, and 3) cows surviving for several parities thereby exploiting the benefits of a suitably mature herd. The herds in the present study are, on average, not reaching these targets. Heifers are calving at over 30 mo of age and the average calving interval is $384 \mathrm{~d}$ implying a delay in the median calving date of the mature herd. Results from this study suggest that genetic selection may help achieve the reproduction targets for a seasonal calving beef cow.

Agreeing with many previous studies in beef cattle (Koots et al., 1994; Donoghue et al., 2004; Forni and Albuquerque, 2005) as well as the vast quantity of studies in dairy cattle (Pryce and Veerkamp, 2001; Berry et al., 2013), both the heritability and repeatability of the traditional reproduction traits was low. Some studies in beef cattle (Goyache et al., 2005; Roughsedge et al., 2005; Urioste et al., 2007; Van Melis et al., 2010) documented higher heritability estimates for reproduction traits but these datasets were generally small in size. Greater heritability estimates are sometimes reported for age at first calving relative to other reproduction traits (Koots et al., 1994; Gutiérrez et al., 2002) agreeing with the present study. Similarly, Phocas and Sapa (2004) reported a heritability of 0.02 to 0.17 for the observation of estrus at 15 mo of age in Charolais, Limousin, and Blonde d'Aquitaine heifers, which should be correlated with age at first calving. Age at first calving is likely to be closely related to the onset of puberty and therefore growth rate. Growth rate or live weight is known to be highly heritable (Crowley et al., 2010; McHugh et al., 2011) and therefore a high heritability for age at first calving is somewhat expected given its likely association. Moreover, heritability estimates for the onset of puberty in human populations are 0.50 to 0.80 (Palmert and Boepple, 2001).

The moderate heritability estimates in the present study for the nonreproduction traits agree within international estimates for live weight (Koots et al., 1994; Phocas and Sapa, 2004), carcass traits (Koots et al., 1994; Marshall, 1994; Hoque et al., 2006), and type traits (Koots et al., 1994; Gutiérrez et al., 2002; Bouquet et al., 2010) and have been discussed in detail elsewhere for Irish cattle (McHugh et al., 2010, 2011; Pabiou et al., 2011) using data similar to that used in the present study.

Considerable genetic variation in reproduction traits clearly exists in the sample population used in the present study. Since calving dates, and therefore dates of birth, are legally required to be recorded on all cattle 
born in Ireland (and within the European Union), routine access to all traits evaluated in the present study for inclusion in genetic evaluations is a reality. The limiting factor is therefore ample sized progeny groups to increase the accuracy of selection for these low heritability traits. This study clearly shows, however, that the accuracy of genetic evaluations for reproductive performance can be augmented by exploiting the information from routinely available predictor traits.

\section{Genetic Correlations}

Irrespective of whether evaluated by trained assessors on live animals or based on mechanical grading of carcass conformation, greater genetic merit for muscularity was generally associated with reduced CALV42 and longer calving intervals. This is substantiated by the genetic correlations of both price and weanling quality with reproductive performance since moderate to strong genetic correlations have previously been reported between increased muscularity and greater animal price (McHugh et al., 2012) as well as there being a very likely strong contribution of muscularity to a producer's perception of weanling quality. All of these traits, with the possible exception of weanling quality, are relatively independent of live weight; animal price is phenotypically independent of animal live weight since live weight was included as a covariate in the statistical model. Therefore, because of the genetic correlation between live weight and reproductive performance, the antagonistic genetic effect of selection for muscularity on reproductive performance can be exacerbated further by simultaneously selecting for increased live weight or growth rate.

There is a paucity of information on the genetic relationships between both muscularity and live weight traits with female reproductive performance in cattle. Roughsedge et al. (2005) reported genetic correlations between visually assessed muscle score of live animals and age at first calving, calving interval, and lifespan. The genetic correlations, however, varied considerably between the 4 breeds evaluated and many of the SE of the correlations were very large or not estimated. Phocas (2009) in an analysis of French Charolais cattle reported that greater muscularity was negatively genetically correlated $(-0.53$ to -0.44$)$ with calving success to first insemination in heifers while positive genetic correlations ( 0.44 to 0.47$)$ existed between subjectively scored skeletal size and calving success to first insemination. Gutiérrez et al. (2007) documented genetic correlations between calving interval and both birth and weaning weight of $0.15 \pm 0.114$ and $-0.07 \pm 0.112$, respectively; the genetic correlation between maternal weaning weight and direct calving difficulty in that study was $-0.15 \pm$ 0.11 , which is opposite to the positive genetic correlation $(0.39 \pm 0.10)$ in the present study. Ilatsia et al. (2011)re- ported a negative genetic correlation $(-0.50)$ between mature live weight and calving interval in Sahiwal cattle in semiarid Kenya. Corroborating the present study, Crowley et al. (2011), using data from Irish performance tested bulls and their commercial relatives, reported inferior female reproductive performance in genetically heavier or faster growing beef animals. Mercadante et al. (2003), however, reported no difference in days to calving among females divergently selected over successive generations for yearling live weight; however, selection bias in the long-term experiment may have hindered detection of significant differences between the selection lines since only progeny from cows that conceived were retained. Gutiérrez et al. (2002), using data also from seasonal calving beef herds, reported genetic merit for increased animal size and a deeper body was associated with shorter calving interval while genetic merit for thigh development was not correlated with calving interval. Nonetheless, agreeing with the present study Gutiérrez et al. (2002) reported a positive genetic correlation between body size, body depth, and thigh development with age at first calving in Asturiana de los Valles beef cattle. However, the genetic correlation between calving interval and age at first calving was positive $(0.23 \pm 0.08)$ in the dataset analyzed by Gutiérrez et al. (2002), agreeing with the present study. Although estimates of correlations between type traits and reproductive performance are lacking in beef, there are a plethora of genetic studies that have correlated type traits and reproductive performance in dairy cattle (Pryce et al., 2000; Berry et al., 2004). There was a general consensus from those studies (Pryce et al., 2000; Berry et al., 2004) that larger dairy cows had inferior reproductive performance. In their genetic analysis of age at puberty in a multibreed U.S. beef population, Gregory et al. (1995) documented near 0 to positive genetic correlations ( 0.02 to 0.17 ) between hip height and age at puberty.

There is also a lack of genetic studies that have attempted to relate body fatness (e.g., BCS) to reproductive performance in beef cows although several phenotypic studies in beef cows (Selk et al., 1988; Drennan and Berry, 2006) clearly demonstrate an association between BCS (change) in live animals and reproductive performance agreeing with the many phenotypic studies in dairy cattle (Roche et al., 2009). Similarly there is a general consensus in dairy cattle that genetic merit for increased BCS is associated with improved reproductive performance (Berry et al., 2003). These results all corroborate the genetic correlations between increased carcass subcutaneous fat level and greater CALV42 and shorter calving interval observed in the present study; genetic correlations between BCS itself and reproductive performance were less consistent but were nonetheless associated with larger SE. Although not consistent across breeds, Roughsedge et al. (2005) reported negative or near zero genetic correlations ( -0.33 to 0.05$)$ between ultrasound measure of 
backfat depth of approximately 400-d-old cattle and calving interval in U.K. cattle; genetic correlations between fat depth and age at first calving varied considerably between the four breeds evaluated but with large associated SE. Gregory et al. (1995), when evaluating genetic parameters for age at puberty (similar trait to age at first calving) across multiple purebred and composite beef breeds, reported negative ( -0.17 to -0.09 ; SE of 0.11 to $0.14)$ genetic correlations between BCS at 2 and $5 \mathrm{yr}$ of age and age at puberty.

Few beef studies, most likely due to the lack of data on a sufficient numbers of animals, have attempted to quantify the genetic associations between calving difficulty and reproductive performance. Roughsedge et al. (2005), using data from British Angus, Limousin, Simmental and South Devon cattle, reported genetic correlations between both direct and maternal calving difficulty with age at first calving, calving interval, and lifespan. Although the SE of the correlations were large and the correlations sometimes differed by breed, there was a general tendency for negative or close to zero genetic correlations $(-0.23$ to 0.03$)$ between age at first calving and direct calving difficulty. With the exception of the Simmental breed, the genetic correlation between maternal calving difficulty and age at first calving was positive ( 0.07 to 0.12 ). These are directly opposite to the correlations observed in the present study although the SE reported by Roughsedge et al. (2005) do not imply that their estimates were different to those in the present study. The positive genetic correlations (0.07 to 0.15 ) reported by Phocas (2009) in a large population of French Charolais cattle between direct calving difficulty and calving success to first insemination in heifers were also associated with large SE (0.26 to 0.27$)$.

The genetic correlations reported by Roughsedge et al. (2005) between maternal calving difficulty and calving interval were positive or close to zero $(-0.05$ to 0.38$)$ agreeing with the positive genetic correlation between maternal calving difficulty and calving interval in the present study (0.32). These genetic correlations as well as the positive genetic correlation of 0.49 between calving difficulty and calving interval in Asturianna de los Valles beef cattle (Gutiérrez et al., 2007) also agree with the phenotypic associations between calving difficulty and compromised reproductive performance in beef (Laster et al., 1973) and dairy (Berry et al., 2007) cattle.

\section{Conclusions}

Consistent with the plethora of studies in dairy cows (Pryce and Veerkamp, 2001; Berry et al., 2003), low heritability estimates exist for reproduction traits in beef cows, estimated using a large national database in commercial crossbred cows. The low heritability of the reproduction traits, coupled with the long time pe- riod to measure many of these traits, imply that predictor traits, measurable at a low marginal cost early in the life of the animal or its relatives, could be very useful to increase the accuracy of selection. Several potential predictor traits, genetically correlated with reproductive performance, most of which are already routinely available at no extra cost, were identified. These traits related predominantly to the conformation (e.g., muscularity) and weight of the live or slaughtered animal. Furthermore, two heritable traits, weanling quality and docility, scored subjectively by producers were moderately correlated (absolute correlations varied from 0.15 to 0.54 ) with reproductive performance signifying the benefit of producer scored traits as useful predictors of performance. Clear benefits exist from including correlated predictor traits in national multitrait genetic evaluations for reproductive performance. Nevertheless, actual recording of reproduction phenotypes is still necessary to achieve high accuracy of genetic selection and resolve genetic antagonisms with terminal traits. Because of the unfavorable genetic correlation between muscularity and reproductive performance, breeding objectives with selective pressure on muscularity need to take cognizance of reproductive performance, or at least some indicator of reproductive performance (e.g., BCS), to ameliorate any deterioration in the reproductive performance of the selection line, breed, or population.

\section{LITERATURE CITED}

Berry, D. P., F. Buckley, P. Dillon, R. D. Evans, M. Rath, and R. F. Veerkamp. 2003. Genetic parameters for body condition score, body weight, milk yield, and fertility estimated using random regression models. J. Dairy Sci. 86:3704-3717.

Berry, D. P., F. Buckley, P. G. Dillon, R. D. Evans, and R. F. Veerkamp. 2004. Genetic relationships among linear type traits, milk yield, body weight, fertility and somatic cell count in primiparous dairy cows. Ir. J. Agric. Food Res. 43:161-176.

Berry, D. P., J. F. Kearney, K. Twomey, and R. D. Evans. 2013. Genetics of reproductive performance in seasonal calving dairy cattle production systems. Ir. J. Agric. Food Res. 52:1-16.

Berry, D. P., J. M. Lee, K. A. Macdonald, and J. R. Roche. 2007. Body condition score and body weight effects on dystocia and stillbirths and consequent effects on post-calving performance. J. Dairy Sci. 90:4201-4211.

Bormann, J. M., L. R. Totir, S. D. Kachman, R. L. Fernando, and D. E. Wilson. 2006. Pregnancy rate and first-service conception rate in Angus heifers. J. Anim. Sci. 84:2022-2025.

Bouquet, A., M.-N. Fouilloux, G. Renand, and F. Phocas. 2010. Genetic parameters for growth, muscularity, feed efficiency and carcass traits of young beef bulls. Livest. Sci. 129:38-48.

Brotherstone, S. 1994. Genetic and phenotypic correlations between linear type traits and production traits in Holstein-Friesian dairy cattle. Anim. Prod. 59:183-187.

Crowley, J. J., R. D. Evans, N. McHugh, D. A. Kenny, M. McGee, D. H. Crews Jr., and D. P. Berry. 2011. Genetic relationships between feed efficiency in growing males and beef cow performance. J. Anim. Sci. 88:885-894.

Crowley, J. J., D. A. Kenny, M. McGee, D. H. Crews Jr., R. D. Evans, and D. P. Berry. 2010. Phenotypic and genetic parameters for different measures of feed efficiency in different breeds of Irish performance-tested beef bulls. J. Anim. Sci. 88:885-894. 
Crump, R. E., N. R. Wray, R. Thompson, and G. Simm. 1997. Assigning pedigree beef performance records to contemporary groups taking account of within-herd calving patterns. Anim. Sci. 65:2193-2198.

Donoghue, K. A., R. Rekaya, J. K. Bertrand, and I. Misztal. 2004. Genetic evaluation of calving to first insemination using natural and artificial insemination mating data. J. Anim. Sci. 82:362-367.

Drennan, M. J., and D. P. Berry. 2006. Factors affecting body condition score, live weight and reproductive performance in springcalving suckler cows. Ir. J. Agric. Food Res. 45:25-38.

Evans, J. L., B. L. Golden, R. M. Bourdon, and K. L. Long. 1999. Additive genetic relationships between heifer pregnancy and scrotal circumference in Hereford cattle. J. Anim. Sci. 77:2621-2628.

Forni, S., and L. G. Albuquerque. 2005. Estimates of genetic correlations between days to calving and reproductive and weight traits in Nelore cattle. J. Anim. Sci. 83:1511-1515.

Gilmour A. R., B. J. Gogel, B. R. Cullis, and R. Thompson. 2009. ASReml user guide release 3.0. VSN International Ltd., Hemel Hempstead, UK.

Goyache, F., J. P. Gutiérrez, I. Fernández, L. J. Royo, and I. Álvarez. 2005. Genetic analysis of days open in beef cattle. Livest. Prod. Sci. 93:283-289.

Gregory, K. E., L. V. Cundiff, and R. M. Koch. 1995. Genetic and phenotypic (co)variances for production traits of female populations of purebred and composite beef cattle. J. Anim. Sci. 73:2235-2242.

Gutiérrez, J. P., I. Álvarez, I. Fernández, L. J. Royo, J. Díez, and F. Goyache. 2002. Genetic relationships between calving date, calving interval, age at first calving and type traits in beef cattle. Livest. Prod. Sci. 78:215-222.

Gutiérrez, J. P., F. Goyache, I. Fernández, I. Alvarez, and L. J. Royo. 2007. Genetic relationships among calving ease, calving interval, birth weight, and weaning weight in the Asturina de los Valles beef cattle breed. J. Anim. Sci. 85:69-75.

Hickey, J. M., M. G. Keane, D. A. Kenny, A. R. Cromie, and R. F. Veerkamp. 2007. Genetic parameters for EUROP carcass traits within different groups of cattle in Ireland. J. Anim. Sci. 85:314-321

Hoque, M. A., P. F. Arthur, K. Hiramoto, and T. Oikawa. 2006. Genetic relationship between different measures of feed efficiency and its component traits in Japanese Black (Wagyu) bulls. Livest. Sci. 99:111-118.

Ilatsia, E. D., S. A. Migose, W. B. Muhuyi, and A. K. Kahi. 2011. Sahiwal cattle in semi-arid Kenya: Genetic aspects of growth and survival traits and their relationship to milk production and fertility. Trop. Anim. Health Prod. 43:1575-1582.

Koots, K. R., J. P. Gibson, C. Smith, and J. W. Wilton. 1994. Analysis of published genetic parameter estimates for beef production traits. 1. Heritability. Anim. Breed. Abstr. 62:309-338.

Laster, D. B., H. A. Glimp, L. V. Cundiff, and K. E. Gregory. 1973. Factors affecting dystocia and the effects of dystocia on subsequent reproduction in beef cattle. J. Anim. Sci. 36:695-705.

Marshall, D. M. 1994. Breed differences and genetic parameters for body composition trait in beef cattle. J. Anim. Sci. 72:2745-2755.

Martínez-Velázquez, G., K. E. Gregory, G. L. Bennett, and L. D. Van Vleck. 2003. Genetic relationships between scrotal circumference and female reproductive traits. J. Anim. Sci. 81:395-401.

McHugh, N., R. D. Evans, P. R. Amer, A. G. Fahey, and D. P. Berry. 2011. Genetic parameters for cattle price and live-weight from routinely collected data at livestock auctions and commercial farms. J. Anim. Sci. 89:29-39.
McHugh, N., R. D. Evans, A. G. Fahey, and D. P. Berry. 2012. Animal muscularity and size are genetically correlated with animal live-weight and price. Livest. Sci. 144:11-19.

McHugh, N., A. G. Fahey, R. D. Evans, and D. P. Berry. 2010. Factors associated with selling price of cattle at livestock auctions. Animal 8:1378-1389.

Melton, B. E. 1995. Conception to consumption: The economics of genetic improvement. In: Proc. Beef Improvement Federation 27th Research Symposium and Annual Meeting, Sheridan, WY.

Mercadante, M. E. Z., I. U. Packer, A. G. Razook, J. N. S. G. Cyrillo, and L. A. Figueiredo. 2003. Direct and correlated responses to selection for yearling weight on reproductive performance of Nelore cows. J. Anim. Sci. 81:376-384.

Meyer, K., K. Hammond, M. J. Mackinnon, and P. F. Parnell. 1991. Estimates of covariance between reproduction and growth in Australian beef cattle. J. Anim. Sci. 69:3533-3543.

Pabiou, T., W. F. Fikse, P. R. Amer, A. R. Cromie, A. Näsholm, and D. P. Berry. 2011. Genetic variation in wholesale carcass cuts predicted from digital images in cattle. Animal 5:1720-1727.

Palmert, M. R., and P. A. Boepple. 2001. Variation in the timing of puberty: Clinical spectrum and genetic investigation. J. Clin. Endocrinol. Metab. 86:2364-2368.

Phocas, F. 2009. Genetic analysis of breeding traits in a Charolais cattle population segregating an inactive myostatin allele. J. Anim. Sci. 87:1865-1871.

Phocas, F., and J. Sapa. 2004. Genetic parameters for growth, reproductive performance, calving ease and suckling performance in beef cattle heifers. Anim. Sci. 79:41-48.

Pryce, J. E., M. P. Coffey, and S. Brotherstone. 2000. The genetic relationship between calving interval, body conditions core and linear type and management traits in registered Holsteins. J. Dairy Sci. 83:2664-2671.

Pryce, J. E., and R. F. Veerkamp. 2001. The incorporation of fertility indices in genetic improvement programmes. In: M. G. Diskin, editor, Fertility in the high-producing dairy cow. Occasional Publication No 26. British Society of Animal Science, Edinburgh, Scotland. p. 223-236.

Roche, J. R., N. C. Friggens, J. K. Kay, M. W. Fisher, K. J. Stafford, and D. P. Berry. 2009. Body condition score and its association with dairy cow productivity, health, and welfare: A review. J. Dairy Sci. 92:5769-5801.

Roughsedge, T., P. R. Amer, R. Thompson, and G. Simm. 2005. Genetic parameters for a maternal breeding goal in beef production. J. Anim. Sci. 83:2319-2329.

Schmitz, F., R. W. Everett, and R. L. Quaas. 1991. Herd-year-season clustering. J. Dairy Sci. 74:629-636.

Selk, G. E., R. P. Wettemann, K. S. Lusby, J. W. Oltjen, S. L. Mobley, R. J. Rasby, and J. C. Garmendia. 1988. Relationships among weight change, body condition and reproductive performance of range beef cows. J. Anim. Sci. 66:3153-3159.

Urioste, J. I., I. Misztal, and J. K. Bertrand. 2007. Fertility traits in spring-calving Aberdeen Angus cattle. 1. Model development and genetic parameters. J. Anim. Sci. 85:2854-2860.

Van Melis, M. H., J. P. Eler, G. J. M. Rosa, J. B. S. Ferraz, L. G. G. Figueiredo, E. C. Mattos, and H. N. Oliveira. 2010. Additive genetic relationships between scrotal circumference, heifer pregnancy, and stayability in Nellore cattle. J. Anim. Sci. 88:3809-3813.

VanRaden, P. M., and A. H. Sanders. 2003. Economic merit of crossbred and purebred US dairy cattle. J. Dairy Sci. 86:1036-1044.. 